\title{
Seroprevalence and genetic characterization of Toxoplasma gondii in three species of pet birds in China
}

\author{
Wei Cong ${ }^{1,2}$, Qing-Feng Meng ${ }^{3}$, Hui-Qun Song ${ }^{1}$, Dong-Hui Zhou', Si-Yang Huang ${ }^{1}$, Ai-Dong Qian²,
} Chunlei Su, and Xing-Quan Zhu, ${ }^{1,2^{*}}$

\begin{abstract}
Background: Toxoplasmosis, caused by the protozoan parasite Toxoplasma gondii, is one of the most common zoonosis worldwide, affecting a wide range of warm-blooded mammals and birds worldwide. However, no information on T. gondii infection in pet birds in China is available. Therefore, this study was performed to determine the prevalence of T. gondii infection in pet birds in Gansu province, China.

Methods: A total of 687 blood samples were collected from pet birds (Carduelis spinus, Alauda gulgula, Cocothraustes migratorlus) in three representative administrative regions in Gansu province, northwest China between August 2011 and September 2012 T. gondii antibodies were determined using the modified agglutination test (MAT). Genomic DNA was extracted from the brain tissues of seropositive pet birds and T. gondii B1 gene was amplified using a semi-nested PCR.DNA samples giving positive B1 amplification were then genetically characterized using multi-locus PCR-RFLP.

Results: The overall T. gondii seroprevalence was $11.21 \%$ (77/687). C. spinus had the highest T. gondii seroprevalence (11.65\%), followed by A. arvensis (11.39\%) and C. migratorlus (5.26\%), these differences were not statistically significant $(P>0.05)$. Of 77 DNA samples, 8 were positive for the T. gondii B1 gene, four showed complete genotyping results. Only one genotype (the Type II variant: ToxoDB genotype \#3) was identified.

Conclusions: The results of the present survey indicated the presence of T. gondii infection in pet birds in Gansu province, China. These data provide base-line information for the execution of control strategies against T. gondii infection in pet birds. To our knowledge, this is the first report documenting the occurrence of $T$. gondii prevalence and genotype in pet birds in China.
\end{abstract}

Keywords: Toxoplasma gondii, Toxoplasmosis, Pet birds, Seroprevalence, Genetic characterization

\section{Background}

Toxoplasmosis is one of the most common zoonosis worldwide caused by the protozoan parasite Toxoplasma gondii. It is estimated that T. gondii infects up to onethird of the human population in the world [1]. Humans are infected by ingesting oocysts shed by cats or consuming under-cooked meat with parasite tissue cysts [2].

\footnotetext{
*Correspondence: xingquanzhu1@hotmail.com

'State Key Laboratory of Veterinary Etiological Biology, Key Laboratory of Veterinary Parasitology of Gansu Province, Lanzhou Veterinary Research Institute, Chinese Academy of Agricultural Sciences, Lanzhou, Gansu Province 730046, PR China

${ }^{2}$ College of Animal Science and Technology, Jilin Agricultural University, Changchun, Jilin Province 130118, PR China

Full list of author information is available at the end of the article
}

It can cause severe disease in the fetus during congenital infection, and can be fatal to immunocomprimised patients such as those with AIDS or organ transplant [3,4]. $T$. gondii infects a wide range of animals, including mammals and birds. In spite of the high prevalence of toxoplasmosis reported for several species of wild birds around the world [5], there is yet no information in pet birds.

Pet birds are very important to public health because they may act as natural reservoirs for many pathogens, such as Newcastle disease virus, Avian influenza virus, Chlamydia psittaci and others pathogens [6-9], and they have also been proved to be important infection sources for a variety of etiologic agents. In China, pet birds have been raised and kept over a long period of history for 
companionship and entertainment, and they maintain close contact with humans, especially in urban areas. Urban areas provide a particular and complicated environment where closely interacting biological and social constraints may either directly or indirectly impact on the presence of $T$. gondii in pet birds, particularly, pet birds are frequently taken to the park by their owners, can easily come into contact with the stray cats and stray dogs. Usually, $T$. gondii infection in pet birds is not harmful for humans. However, dead pet birds both from pet shops and from households are often thrown away without any bio-safety considerations. The dead birds may be eaten by cats and, if the birds contained T. gondii, the cats may become infected with the parasite and subsequently shed oocysts. Humans can become infected postnatally via ingesting $T$. gondii tissue cysts from water, vegetables, fruits and other food contaminated with $T$. gondii oocysts. In addition, pet birds share nearly the same environment with people in urban areas, such as water, food and others, so the investigation of $T$. gondii infection in pet birds might be suitable to estimate the risk of $T$. gondii infection in urban residents. In China, Eurasian Siskin (Carduelis spinus), Oriental Skylark (Alauda gulgula) and Black-tailed Grosbeak (Cocothraustes migratorlus) are very popular as pet birds. Here we conducted a study on the seroprevalence and genotyping of $T$. gondii in these pet birds in Gansu province, China.

\section{Methods}

\section{Ethics statement}

The present study was approved by the Animal Ethics Committee of Lanzhou Veterinary Research Institute, Chinese Academy of Agricultural Sciences (Permit code LVRIAEC2011-009). Birds from which serum samples were collected were handled in accordance with the Animal Ethics Procedures and Guidelines of the People's Republic of China.

\section{The site}

The present investigation was carried out in Gansu province, China. Gansu has an area of 454,000 square kilometres, and the vast majority of its land is more than 1,000 meters above sea level. It lies between the Tibetan Plateau and the Loess Plateau, the province contains the geographical center of China, marked by the Center of the Country Monument at $35^{\circ} 50^{\prime} 40.9^{\prime} \mathrm{N} 103^{\circ} 27^{\prime} 7.5^{\prime \prime} \mathrm{E}$. Gansu generally has a semi-arid to arid, continental climate, with warm to hot summers and cold to very cold winters. Most of the precipitation is delivered in the summer months.

\section{Collection and preparation of serum samples}

A total of 687 blood samples were collected between August 2011 and September 2012 from pet birds of three species in three representative administrative regions in Gansu province, China (Table 1). All bird samples from pet markets were collected randomly, and one blood sample was collected from each bird. Blood samples were then centrifuged at 3,000 $\mathrm{g}$ for $10 \mathrm{~min}$, and serum was collected, frozen, and stored at $-20^{\circ} \mathrm{C}$ until use.

\section{Serological examination}

The pet bird serum samples were tested for $T$. gondii antibodies by the modified agglutination test (MAT) as described previously $[10,11]$. Briefly, sera were added to the "U" bottom of 96-well microtiter plates, and diluted 2-fold starting from 1:5 to 1:160. Bird sera with MAT titers of 1:5 or higher were considered positive for T. gondii antibodies based on a previous study [12], those sera with doubtful reactions were re-tested, and positive and negative controls were included in each test.

\section{DNA extraction and genetic characterization of $T$. gondii isolates}

The brain tissues of seropositive pet birds were used for DNA extraction. Genomic DNA was extracted from these tissues using TIANamp Genomic DNA kit (Tian$\mathrm{Gen}^{\mathrm{n} w}$, Beijing, China) according to manufacturer's recommendations. In brief, $30 \mathrm{mg}$ of the tissues were treated with sodium dodecyl sulphate/proteinase $\mathrm{K}$ at $56^{\circ} \mathrm{C}$ for $5 \mathrm{~h}$ digestion in a thermostat water bath. DNA samples were prepared after purification by silica gel column chromatography and eluted into $50 \mu \mathrm{l}$ elution buffer. Then, a semi-nested PCR targeting the T. gondii B1 gene was performed to detect possible infection with $T$. gondii [13]. DNA samples giving positive B1 amplification were then used for genetic characterization. Genotyping was conducted using 10 genetic markers for PCRRFLP (i.e., SAG1, SAG2, alter.SAG2, SAG3, BTUB, GRA6, c22-8, L358, PK1, and Apico), as previously described [14-18]. Six reference T. gondii strains were included as the positive controls including GT1, PTG, CTG, MAS, TgCgCa1 and $\mathrm{TgCatBr} 5$. The PCR reaction $(25 \mu \mathrm{l})$ composed of $1 \times$ PCR buffer, $0.2 \mathrm{mM}$ of each primer, $200 \mu \mathrm{M}$ dNTPs, $2 \mathrm{mM} \mathrm{MgCl}$, $0.2 \mathrm{U}$ of HotStart Taq DNA polymerase (TAKARA, Japan). The PCR amplification was performed using a thermal cycler (PTC 200, Bio-RAD). All samples were incubated at $95^{\circ} \mathrm{C}$ for 5 min to activate the DNA polymerase, then 30 cycles of PCR at $95^{\circ} \mathrm{C}$ for $30 \mathrm{~s}, 55^{\circ} \mathrm{C}$ for $60 \mathrm{~s}$ and $72^{\circ} \mathrm{C}$ for $90 \mathrm{~s}$. Multiplex PCR-amplified products were diluted 1:1 in sterile, double-distilled water, and then used for nested PCR amplifications with internal primers for each marker, separately $[19,20]$. A similar program was used for the nested PCR. The nested PCR amplifications were performed with the annealing temperature at $60^{\circ} \mathrm{C}$ for $60 \mathrm{~s}$ for all the markers except Apico, which was amplified at $55^{\circ} \mathrm{C}$. The nested PCR products were digested 
Table 1 Prevalence of Toxoplasma gondii infection in three species of pet birds (Carduelis spinus, Alauda gulgula and Cocothraustes migratorlus) in China

\begin{tabular}{|c|c|c|c|c|c|c|c|c|c|c|}
\hline \multirow[t]{2}{*}{ Host } & \multirow[t]{2}{*}{ Locations } & \multicolumn{6}{|c|}{ No. of sera with MAT titers of } & \multirow[t]{2}{*}{ No. examined } & \multirow[t]{2}{*}{ No. positive } & \multirow{2}{*}{$\begin{array}{l}\text { Prevalence (\%) } \\
(95 \% \mathrm{Cl})\end{array}$} \\
\hline & & $1: 5$ & $1: 10$ & $1: 20$ & $1: 40$ & $1: 80$ & $1: 160$ & & & \\
\hline \multirow[t]{3}{*}{ C. spinus } & Lanzhou & 5 & 4 & 6 & 2 & 2 & 0 & 120 & 19 & $15.83(9.30-22.37)$ \\
\hline & Tianshui & 4 & 2 & 2 & 2 & 0 & 0 & 120 & 10 & $8.33(3.89-13.28)$ \\
\hline & Longnan & 1 & 8 & 2 & 0 & 1 & 0 & 120 & 12 & $10.00(4.63-15.37)$ \\
\hline \multirow[t]{3}{*}{ A. gulgula } & Lanzhou & 5 & 3 & 3 & 3 & 2 & 1 & 135 & 17 & $12.59(7.00-18.19)$ \\
\hline & Tianshui & 2 & 2 & 3 & 4 & 0 & 0 & 73 & 11 & $15.07(6.86-23.28)$ \\
\hline & Longnan & 1 & 1 & 3 & 1 & 0 & 0 & 81 & 6 & $7.41(1.70-13.11)$ \\
\hline C. migratorlus & Tianshui & 1 & 1 & 0 & 0 & 0 & 0 & 38 & 2 & $5.26(0.00-12.36)$ \\
\hline Total & & 19 & 21 & 19 & 12 & 5 & 1 & 687 & 77 & $11.21(8.85-13.57)$ \\
\hline
\end{tabular}

with restriction enzymes for $1 \mathrm{~h}$, and the temperature for each enzyme was used according to the instructions for each enzyme. The restriction fragments were resolved in $2.5 \%-3 \%$ agarose gel, stained by the GoldenView $^{\text {TM }}$, and photographed using a gel documentation system (UVP GelDoc-ItTM Imaging System, Cambridge, U.K.).

\section{Statistical analysis}

Differences in the seroprevalence of $T$. gondii-infected pet birds among different variables including location, age, gender and species were analyzed using a Chisquare test by SAS (Statistical Analysis System, Version 8.0). Results were considered statistically significant when $P<0.05$. These variables were also evaluated in the binary Logit model as independent variables by forward stepwise regression analysis to test the seroprevalence (response variable) in the multivariable regression analysis. The best model was judged by the Fisher's scoring algorithm. The effects could be included in the model when $P<0.05$.

\section{Results}

The overall seroprevalence of $T$. gondii in the examined pet birds was $11.21 \%$ (77/687, 95\% confidence interval [CI] 8.85-13.57). Of these, A. gulgula had the highest $T$. gondii seroprevalence (11.77\%, 95\% CI 8.05-15.48), followed by C. spinus (11.39\%, 95\% CI 8.11-14.67) and C. migratorlus (5.26\%, 95\% CI 0.00-12.36).

No statistically significant difference was found in the seroprevalence of $T$. gondii between male pet birds (10.84\%, 95\% CI 7.85-13.84) and female pet birds (11.77\%, 95\% CI 7.94-15.5, $\mathrm{P}=0.708)$. The prevalence in adult pet birds $(13.20 \%$, 95\% CI 10.28-16.13) was significantly higher than that in juvenile pet birds $(5.23 \%, 95 \%$ CI 1.91-8.56, OR =2.76, 95\% CI 1.34-5.65, $P=0.004)$. Statistical analysis of the originating regions showed that pet birds from Lanzhou had a higher $T$. gondii seropositivity (14.12\%, 95\% CI 9.84-18.39) than the birds from Tianshui (9.96\%, 95\% CI 6.10-13.82) and Longnan (8.96\%, 95\% CI 5.01-12.90), but the difference was not statistically significant $(P=0.169)$ (Table 2$)$. In the multivariable regression analysis, no risk factors could be

Table 2 Analysis of the variables associated with Toxoplasma gondii seroprevalence in three species of pet birds (Carduelis spinus, Alauda gulgula and Cocothraustes migratorlus) in China

\begin{tabular}{|c|c|c|c|c|c|c|}
\hline Variable & Category & No. tested & No. positive & $\%(95 \% \mathrm{Cl})$ & $P$ - value & OR $(95 \% \mathrm{Cl})$ \\
\hline \multirow[t]{3}{*}{ Region } & Longnan & 201 & 18 & $8.96(5.01-12.90)$ & 0.169 & Reference \\
\hline & Tianshui & 231 & 23 & 9.96 (6.10-13.82) & & $1.12(0.59-2.15)$ \\
\hline & Lanzhou & 255 & 36 & $14.12(9.84-18.39)$ & & $1.67(0.92-3.04)$ \\
\hline \multirow[t]{2}{*}{ Gender } & Male & 415 & 45 & $10.84(7.85-13.84)$ & 0.708 & Reference \\
\hline & Female & 272 & 32 & $11.77(7.94-15.59)$ & & $1.10(0.68-1.77)$ \\
\hline \multirow[t]{3}{*}{ Species } & Cocothraustes migratorlus & 38 & 2 & $5.26(0.00-12.36)$ & 0.484 & Reference \\
\hline & Alauda gulgula & 289 & 34 & $11.77(8.05-15.48)$ & & $2.40(0.55-10.42)$ \\
\hline & Carduelis spinus & 360 & 41 & $11.39(8.11-14.67)$ & & $2.31(0.54-9.97)$ \\
\hline \multirow[t]{2}{*}{ Age } & Juvenile & 172 & 9 & $5.23(1.91-8.56)$ & 0.004 & Reference \\
\hline & Adult & 515 & 68 & 13.20 (10.28-16.13) & & $2.76(1.34-5.65)$ \\
\hline Total & & 687 & 77 & $11.21(8.85-13.57)$ & & \\
\hline
\end{tabular}


included in the final model because all the $P$ values were above 0.05 .

Of 77 DNA samples, 8 were positive for the T. gondii B1 gene, including 5 from the $C$. spinus and 3 from the A. gulgula. Four DNA samples showed complete genotyping results, 3 from Lanzhou (2 from C. spinus and 1 from A. gulgula) and 1 from Tianshui (from A. gulgula) (Table 3). Another 4 positive samples could not be completely genotyped due to low DNA concentration. Interestingly, only one genotype was identified from the 4 positive samples, which were typed at 10 genetic markers, including 9 nuclear loci, i.e., SAG1, 5' -and 3'SAG2, alternative SAG2, SAG3, GRA6, BTUB, L358, PK1, c22-8 and one an apicoplast locus Apico. These Type II variant strains had type II alleles at all markers except a type I allele at the Apico locus and are considered the Type II variant (ToxoDB genotype \#3).

\section{Discussion}

In this investigation, the overall seroprevalence of $T$. gondii in the examined pet birds was $11.21 \%$ (77/687), which was significantly different from that in wild birds worldwide [5]. The differences in seroprevalences of $T$. gondii in pet birds are probably due to differences in geographical conditions, feeding and living styles, number of cats and rodents, as well as differences in animal husbandry practices and animal welfares.

The $T$. gondii seroprevalence in adult pet birds (13.20\%, 68/515, 95\% CI 10.28-16.13) was significantly higher than that in juvenile pet birds $(5.23 \%, 9 / 172,95 \%$ CI 1.91-8.56, OR $=2.76,95 \%$ CI $1.34-5.65, P=0.004$ ), this result is probably due to the fact that the adult pet birds had more chance to contact with $T$. gondii compared to juvenile pet birds and thus increased the risk of infection, demonstrating that the adult pet birds may significantly increase the probability of $T$. gondii infection.

This result provides evidence that Type II variant genotype prevails in bird populations in mainland China, as recently reported [21]. It is interesting that most $T$. gondii isolates reported in previous studies represent the predominant ToxoDB \#9 in China [21-23]. It seems that this dominant genotype is mostly in the east and southeast regions in China, suggesting population differences among different geographical regions. More studies are needed to investigate this potential difference and the mechanisms that leads to the population structure.

Previous studies $[1,10-12,15]$ have demonstrated that MAT is a sensitive method for measuring antibodies to T. gondii in birds and is considered as an effective serologic method as a guide on isolating $T$. gondii from tissues of birds. In the present study, the antibody titres were diverse; the most frequent level was 1:10 (27.27\%), followed by 1:5 (24.68\%), 1:20 (24.68\%), 1:40 (15.58\%), 1:80 (6.49\%) and 1:60 (1.30\%). PCR with specific primers is regarded as a sensitive and cost-effective assay for detecting T. gondii DNA from biological samples directly [19]. In this study, a semi-nested PCR targeting the $T$. gondii $\mathrm{B} 1$ gene was performed to detect possible infection with $T$. gondii. Of 77 DNA samples, 8 were positive for the T. gondii B1 gene, including 5 from the C. spinus (1 with MAT titer at 1:10, 2 at 1:40, 2 at 1:80) and 3 from the A. gulgula (2 at 1:40, 1 at 1:80). Since no $T$. gondii strain was isolated, the PCR result itself is suggestive, but not the ultimate evidence of infection. Therefore, the results of the present study provided preliminary data for future studies aimed at isolating live parasites in pet birds and confirm the findings.

Humans can acquire $T$. gondii infection from domestic, wild or companion animals [1-4]. Although pets bring a lot of fun and enrich family life, they also pose risks of infectious disease for humans. Due to the current irregular management of pet markets, lack of quarantine and preventive measures, pet diseases continue to spread, and there have been reports of human infection [24-28]. Generally, direct transmission of $T$. gondii from pet birds to humans is unlikely to occur, since the parasites are confined in internal organs and muscles [15,18]. In addition, these pet birds are not

Table 3 Multilocus genotyping of Toxoplasma gondii isolates in pet birds from China by PCR-RFLP analysis

\begin{tabular}{|c|c|c|c|c|c|c|c|c|c|c|c|c|c|}
\hline Isolate ID & Host & Location & SAG1 & $5^{\prime}+3^{\prime}$ SAG2 & Alt. SAG2 & SAG3 & BTUB & GRA6 & $\mathrm{c} 22-8$ & L358 & PK1 & Apico & Genotype \\
\hline GT1 & Goat & United States & । & I & । & I & 1 & । & I & 1 & I & I & Reference, Type I, ToxoDB \#10 \\
\hline PTG & Sheep & United States & $\|/\|$ & $\|$ & $\|$ & $\|$ & $\|$ & $\|$ & $\|$ & $\|$ & $\|$ & $\|$ & Reference, Type II, ToxoDB \#1 \\
\hline CTG & Cat & United States & $\|/\|$ & III & III & III & III & III & III & III & III & III & Reference, Type III, ToxoDB \#2 \\
\hline MAS & Human & France & $\mathrm{u}-1^{*}$ & 1 & $\|$ & III & III & III & $\mathrm{u}-1^{*}$ & 1 & III & 1 & Reference, ToxoDB \#17 \\
\hline TgCgCa1 & Cougar & Canada & । & $\|$ & $\|$ & III & $\|$ & $\|$ & $\|$ & I & $u-2^{*}$ & 1 & Reference, ToxoDB \#66 \\
\hline TgCatBr5 & Cat & Brazil & । & III & III & III & III & III & 1 & 1 & $\mathrm{u}-1^{*}$ & 1 & Reference, ToxoDB \#19 \\
\hline LZES125 & Eurasian Siskin & Lanzhou, China & $\|$ & $\|$ & $\|$ & $\|$ & $\|$ & $\|$ & $\|$ & $\|$ & $\|$ & 1 & Type II variant, ToxoDB \#3 \\
\hline LZES260 & Eurasian Siskin & Lanzhou, China & $\|$ & $\|$ & $\|$ & $\|$ & $\|$ & $\|$ & $\|$ & $\|$ & $\|$ & I & Type II variant, ToxoDB \#3 \\
\hline LZOS124 & Oriental Skylark & Lanzhou, China & $\|$ & $\|$ & $\|$ & $\|$ & $\|$ & $\|$ & $\|$ & $\|$ & $\|$ & 1 & Type II variant, ToxoDB \#3 \\
\hline TSOS188 & Oriental Skylark & Tianshui, China & $\|$ & $\|$ & $\|$ & $\|$ & $\|$ & $\|$ & $\|$ & $\|$ & $\|$ & 1 & Type II variant, ToxoDB \#3 \\
\hline
\end{tabular}

* $\mathrm{u}-1$ and $\mathrm{u}-2$ represent unique RFLP genotypes, respectively. 
usually bred to produce meat for food, therefore they are not likely to transmit $T$. gondii to humans [29]. Surprisingly, during the investigation, we found that the pet shop workers discard dead pet birds as trash without any biosafety measures. In addition, many cats (pet cats and stray cats) are often seen in the pet shops, so they could easily ingest the pet birds due to staff negligence. Once cats and other felids ingest the infected pet birds (alive or dead), tens of millions of oocysts can be shed into the environment in several days, which can potentially infect a variety of animals in large numbers [30], which is a huge safety risk for urban residents.

Epidemiological knowledge regarding the prevalence and risks associated with T. gondii infection in pet birds is unavailable. In China, most pet birds are bred in a semi-free range system, and the birds have opportunities to contact food or water contaminated with $T$. gondii. The results of the present survey revealed the presence of $T$. gondii infection in pet birds in China, which indicated that pet birds may be new reservoirs of $T$. gondii. Pet birds are among the common companion animals of humans. These results indicate existence of this parasite in their environment, which may also pose a risk for human infection. Moreover, investigating the health status of pet birds, facilities, pet shop workers and owners should be an important starting point to evaluate human health risks for zoonotic diseases, and to establish disease control and prevention measures. It is imperative that effective measures for prevention and better control of T. gondii is needed for pet animals. To our knowledge, this is the first report documenting the occurrence of $T$. gondii prevalence in pet birds in China.

\section{Conclusions}

The present study revealed the prevalence of $T$. gondii prevalence in pet birds in China for the first time, and identified the $T$. gondii Type II variant strain (ToxoDB genotype \#3). These data may provide base-line information for the control $T$. gondii infection in pet birds in China.

\section{Competing interests}

The authors declare that they have no competing interests.

\section{Authors' contributions \\ XQZ and CS conceived and designed the study, and critically revised the manuscript. WC, QFM, HQS and DHZ performed the experiments, analyzed the data and drafted the manuscript. SYH and ADQ helped in study design, study implementation and manuscript revision. All authors read and approved the final manuscript.}

\section{Acknowledgments}

Project support was provided in part by the National Natural Science Foundation of China (Grant Nos. 31228022, 31230073 and 31172316) and the Science Fund for Creative Research Groups of Gansu Province (Grant No. 1210RJIA006).

\section{Author details}

'State Key Laboratory of Veterinary Etiological Biology, Key Laboratory of Veterinary Parasitology of Gansu Province, Lanzhou Veterinary Research Institute, Chinese Academy of Agricultural Sciences, Lanzhou, Gansu Province 730046, PR China. ${ }^{2}$ College of Animal Science and Technology, Jilin Agricultural University, Changchun, Jilin Province 130118, PR China. ${ }^{3}$ Jilin Entry-Exit Inspection and Quarantine Bureau, Changchun, Jilin Province 130118, PR China. ${ }^{4}$ Department of Microbiology, the University of Tennessee, Knoxville, TN 37996, USA.

Received: 18 February 2014 Accepted: 29 March 2014

Published: 1 April 2014

\section{References}

1. Dubey JP: Toxoplasmosis of Animals and Humans. secondth edition. Boca Raton, Florida: CRC Press; 2010:313.

2. Elmore SA, Jones JL, Conrad PA, Patton S, Lindsay DS, Dubey JP: Toxoplasma gondii: epidemiology, feline clinical aspects, and prevention. Trends Parasitol 2010, 26:190-196.

3. Zhou P, Chen Z, Li HL, Zheng H, He S, Lin RQ, Zhu XQ: Toxoplasma gondii infection in humans in China. Parasit Vectors 2011, 4:165.

4. Montoya JG, Liesenfeld O: Toxoplasmosis. Lancet 2004, 363:1965-1976.

5. Dubey JP: A review of toxoplasmosis in wild birds. Vet Parasitol 2002, 106:121-153.

6. Pilny AA, Quesenberry KE, Bartick-Sedrish TE, Latimer KS, Berghaus RD: Evaluation of Chlamydophila psittaci infection and other risk factors for atherosclerosis in pet psittacine birds. J Am Vet Med Assoc 2012, 240:1474-1480.

7. Cray C: Infectious and zoonotic disease testing in pet birds. Clin Lab Med 2011, 31:71-85.

8. Shitaye EJ, Grymova V, Grym M, Halouzka R, Horvathova A, Moravkova M, Beran V, Svobodova J, Dvorska-Bartosova L, Pavlik I: Mycobacterium avium subsp. hominissuis infection in a pet parrot. Emerg Infect Dis 2009, 15:617619.

9. Senthuran S, Vijayarani K, Kumanan K, Nainar AM: Pathotyping of Newcastle disease virus isolates from pet birds. Acta Virol 2005, 47:177-182.

10. Cong W, Huang SY, Zhou DH, Xu MJ, Wu SM, Yan C, Zhao Q, Song HQ, Zhu $X \mathrm{Q}$ : First report of Toxoplasma gondii infection in market-sold adult chickens, ducks and pigeons in northwest China. Parasit Vectors 2012, 5:110.

11. Yan C, Yue CL, Qiu SB, Li HL, Zhang H, Song HQ, Huang SY, Zou FC, Liao M, Zhu XQ: Seroprevalence of Toxoplasma gondii infection in domestic pigeon (Columba livia) in Guangdong Province of southern China. Vet Parasitol 2011, 177:371-373.

12. Dubey JP: Toxoplasma gondii infections in chickens (Gallus domesticus): prevalence, clinical disease, diagnosis and public health significance. Zoonoses Public Health 2010, 57:60-73.

13. Hill DE, Chirukandoth S, Dubey JP, Lunney JK, Gamble HR: Comparison of detection methods for Toxoplasma gondii in naturally and experimentally infected swine. Vet Parasitol 2006, 141:9-17.

14. Su C, Shwab EK, Zhou P, Zhu XQ, Dubey JP: Moving towards an integrated approach to molecular detection and identification of Toxoplasma gondii. Parasitol 2010, 137:1-11.

15. Cong W, Huang SY, Zhou DH, Zhang XX, Zhang NZ, Zhao Q, Zhu XQ: Prevalence and genetic characterization of Toxoplasma gondii in House Sparrows (Passer domesticus) in Lanzhou, China. Korean J Parasitol 2013, 51:363-367.

16. Sun H, Wang Y, Zhang Y, Ge W, Zhang F, He B, Li Z, Fan Q, Wang W, Tu C, Li J, Liu Q: Prevalence and genetic characterization of Toxoplasma gondii in bats in Myanmar. Appl Environ Microbiol 2013, 79:3526-3528.

17. El Behairy AM, Choudhary S, Ferreira LR, Kwok OC, Hilali M, Su C, Dubey JP: Genetic characterization of viable Toxoplasma gondii isolates from stray dogs from Giza, Egypt. Vet Parasitol 2013, 193:25-29.

18. Huang SY, Cong W, Zhou P, Zhou DH, Wu SM, Xu MJ, Zou FC, Song HQ, Zhu XQ: First report of genotyping of Toxoplasma gondii isolates from wild birds in China. J Parasitol 2012, 98:681-682.

19. Zhang XX, Lou ZZ, Huang SY, Zhou DH, Jia WZ, Su C, Zhu XQ: Genetic characterization of Toxoplasma gondii from Qinghai vole, Plateau pika and Tibetan ground-tit on the Qinghai-Tibet Plateau, China. Parasit Vectors 2013, 6:291. 
20. Su C, Zhang X, Dubey JP: Genotyping of Toxoplasma gondii by multilocus PCR-RFLP markers: a high resolution and simple method for identification of parasites. Int J Parasitol 2006, 36:841-848.

21. Wang L, Chen H, Liu D, Huo X, Gao J, Song X, Xu X, Huang K, Liu W, Wang Y, Lu F, Lun ZR, Luo Q, Wang X, Shen J: Genotypes and mouse virulence of Toxoplasma gondii isolates from animals and humans in China. PLOS ONE 2013, 8:e53483.

22. Zhou P, Zhang H, Lin RQ, Zhang DL, Song HQ, Su C, Zhu XQ: Genetic characterization of Toxoplasma gondii isolates from China. Parasitol Int 2009, 58:193-195.

23. Jiang HH, Huang SY, Zhou DH, Zhang XX, Su C, Deng SZ, Zhu XQ: Genetic characterization of Toxoplasma gondii from pigs from different localities in China by PCR-RFLP. Parasit Vectors 2013, 6:227.

24. Vanrompay D, Harkinezhad T, van de Walle M, Beeckman D, van Droogenbroeck C, Verminnen K, Leten R, Martel A, Cauwerts K: Chlamydophila psittaci transmission from pet birds to humans. Emerg Infect Dis 2007, 13:1108-1110.

25. Authried G, Andersen A, Sherson DL: A small bird gives severe consequences. Ugeskr Laeger 2011, 173:3185-3196.

26. Renström A, Olsson M, Hedrén M, Johansson SG, van Hage M: Pet shop workers: exposure, sensitization, and work-related symptoms. Allergy 2011, 66:1081-1087.

27. Bellizzi S, Cocco P, Zucca M, D'Andrea I, Sesler S, Monne M, Onida A, Piras G, Uras A, Angelucci E, Gabbas A, Rais M, Nitsch D, Ennas MG: Household contact with pets and birds and risk of lymphoma. Canc Causes Contr 2011, 22:159-165.

28. Maegawa N, Emoto T, Mori H, Yamaguchi D, Fujinaga T, Tezuka N, Sakai N, Ohtsuka N, Fukuse T: Two cases of Chlamydia psittaci infection occurring in employees of the same pet shop. Nihon Kokyuki Gakkai Zasshi 2001, 39:753-757.

29. Boseret G, Losson B, Mainil JG, Thiry E, Saegerman C: Zoonoses in pet birds: review and perspectives. Vet Res 2013, 44:36.

30. Dubey JP, Felix TA, Kwok OC: Serological and parasitological prevalence of Toxoplasma gondii in wild birds from Colorado. J Parasitol 2010, 96:937-939.

doi:10.1186/1756-3305-7-152

Cite this article as: Cong et al:: Seroprevalence and genetic characterization of Toxoplasma gondii in three species of pet birds in China. Parasites \& Vectors 2014 7:152.

\section{Submit your next manuscript to BioMed Central and take full advantage of:}

- Convenient online submission

- Thorough peer review

- No space constraints or color figure charges

- Immediate publication on acceptance

- Inclusion in PubMed, CAS, Scopus and Google Scholar

- Research which is freely available for redistribution 